\title{
The Impact of Social Capital on Entrepreneurial Performance in Agriculture
}

\author{
Xie Guihua ${ }^{1, a}$, Wang Linping ${ }^{2, b^{*}}$ \\ ${ }^{1}$ College of Management Fujian Agricultural and Forestry University College of Business Administration Fujian Business University \\ Fuzhou, China \\ ${ }^{2}$ College of Economics Fujian Agricultural and Forestry University Fuzhou, China
}

\begin{abstract}
In agriculture, social capital plays a major role in entrepreneurial performance. This study divides social capital into bounding social capital and bridging social capital. The data is collected by questionnaire, and the structural equation modeling is used to understand the impact of different social capitals on entrepreneurial performance in agricultural settings. The results show that both bounding social capital and bridging social capital of agricultural entrepreneurs have significant positive impacts on the performance of agricultural entrepreneurship. Agricultural entrepreneurs should strengthen strong relationships with relatives and friends to obtain more bounding social capital, and accumulate heterogeneous resources to develop bridging social capital.
\end{abstract}

\section{INTRODUCTION}

Rural entrepreneurship is different from urban entrepreneurship because the social network of entrepreneurs shows stronger geographical characteristics. Rural entrepreneurs often choose to use geographical social relationships to help enterprises grow. Trust generated by social relations is the entrepreneur's resource in social structure, that is, social capital. Especially, social capital is a special and important asset for agricultural entrepreneurs. It plays a positive role in promoting entrepreneurship activities in rural areas. In the research of agricultural entrepreneurship performance, social capital is one of the resources that most discussed. In the analysis of farmers' social capital, scholars are trying to divide it into different types. A large number of studies have shown that the social capital of agricultural entrepreneurs is conducive to the innovation and growth of agricultural enterprises, and ultimately promote the improvement of entrepreneurial performance, However, previous studies on rural social capital were limited to kinship and geopolitical social capital. Therefore, it is necessary to further explore the impact of bridging and bounding social capital on agricultural entrepreneurial performance.

\section{LITERATURE REVIEW}

\subsection{Social Capital and Entrepreneurial Performance}

Social capital, in individual or social level, is the most important resource of agricultural entrepreneurs. This study focuses on the individual level of social capital of agricultural entrepreneurs. According to Lin [1], this study defined the social capital as the various networks and social resources in the process of agricultural entrepreneurs' entrepreneurship.

Based on the research of Putnam [2], this paper divides social capital into bounding social capital and bridging social capital. The bounding social capital refers to the interaction range, trust and reciprocity formed by the communication and interaction network between agricultural entrepreneurs, their familiar relatives and friends and the agricultural entrepreneurial team. Bridging social capital refers to the social capital formed by the different networks between agricultural entrepreneurs and suppliers, customers, the public, government departments, service organizations, media and intermediaries in the external environment, including the breadth, depth, trust and reciprocity of relationships.

According to organization theory, entrepreneurial performance is entrepreneurial organization performance, which is a measure of entrepreneurial organization's goal completion degree, which is often used to measure the achievement and effectiveness of Entrepreneurship. The performance of farmers' agriculture related entrepreneurship is the achievements and benefits 
achieved by farmers through agriculture related entrepreneurship. When measuring entrepreneurial performance, the focus should be on the comparison of entrepreneurs' achievement before and after entrepreneurship and the comparison of economic benefits between entrepreneurs of the same kind. In this study, the definition of agricultural entrepreneurship performance is: the results obtained by entrepreneurs and the degree to achieve the goals.

\subsection{The Impact of Bounding Social Capital on the Performance of Agricultural Entrepreneurship}

Scholars have found that bounding social capital can provide information on value creation ability. Family members, relatives or friends who often interact provide entrepreneurs with information on raw materials, funds, channels, and internal production management [3][4]. The bounding social capital formed by familiar members can promote the entrepreneurial activities of agricultural entrepreneurs from the aspects of resource provision, emotional support and psychological enhancement. Bounding social capital is helpful on the performance of agricultural entrepreneurship for the following reasons: first, acquaintances or families provide the source of funds for entrepreneurship, making up for the shortage of entrepreneurial labor. The start-up funds of small and micro agricultural entrepreneurship activities in China are all from family members or family members. Second, the labor force in the early stage of entrepreneurship is mainly family members. Some micro businesses even have their own people to participate in. When the agriculture is busy and needs help, there are also established mutual aid behaviors among different entrepreneurial families, which are of great help to the smooth development of agricultural business activities. Third, the entrepreneurial process is full of hardships, and the understanding of family members, relatives and friends and members of the entrepreneurial team will often become the spiritual support of entrepreneurs in difficult times, and enhance their tenacity, so that they will not give up easily. Therefore, this study proposed the following hypothesis:
Hypothesis 1: the bounding social capital has a significant positive impact on the entrepreneurial performance.

\subsection{The Impact of Bridging Social Capital on the Performance of Agricultural Entrepreneurship}

Previous studies have shown that bridging social capital has a positive impact on entrepreneurial performance, specifically in the acquisition of heterogeneous resources, the identification and acquisition of entrepreneurial opportunities, and innovative business ideas. Bridging social capital can provide entrepreneurs with heterogeneous market information. Entrepreneurs can obtain entrepreneurial guidance through different channels, establish informal relationships with people inside and outside the industry, and participate in professional discussions, which can promote the cognition of entrepreneurial opportunities [5].

In agricultural entrepreneurship, entrepreneurship projects are mostly scattered in rural areas, and some entrepreneurial activities are even carried out in remote rural areas. Most of China's agricultural entrepreneurship is small and micro enterprises. Entrepreneurs themselves should participate in agricultural production and operation activities in person, so it is impossible for them to spend too much time, energy and cost to carry out the operation of social capital. Therefore, in the past, farmers' social capital in the rural environment mainly refers to the traditional social capital based on blood relationship, kinship and geography. Because these social capital are familiar with each other, they have few opportunities to obtain heterogeneous resources. In this situation, in traditional rural society, those who can obtain more favorable heterogeneous resources are often some agricultural entrepreneurs whose family members work as civil servants in government departments. They have achieved good entrepreneurial performance because of the heterogeneity of government and business relationship resources. Therefore, this study hypothesized as follows.

Hypothesis 2: the bridging social capital has a significant positive impact on the entrepreneurial performance.

According to the literature review and the hypotheses development, a research model was proposed as Fig. 1.

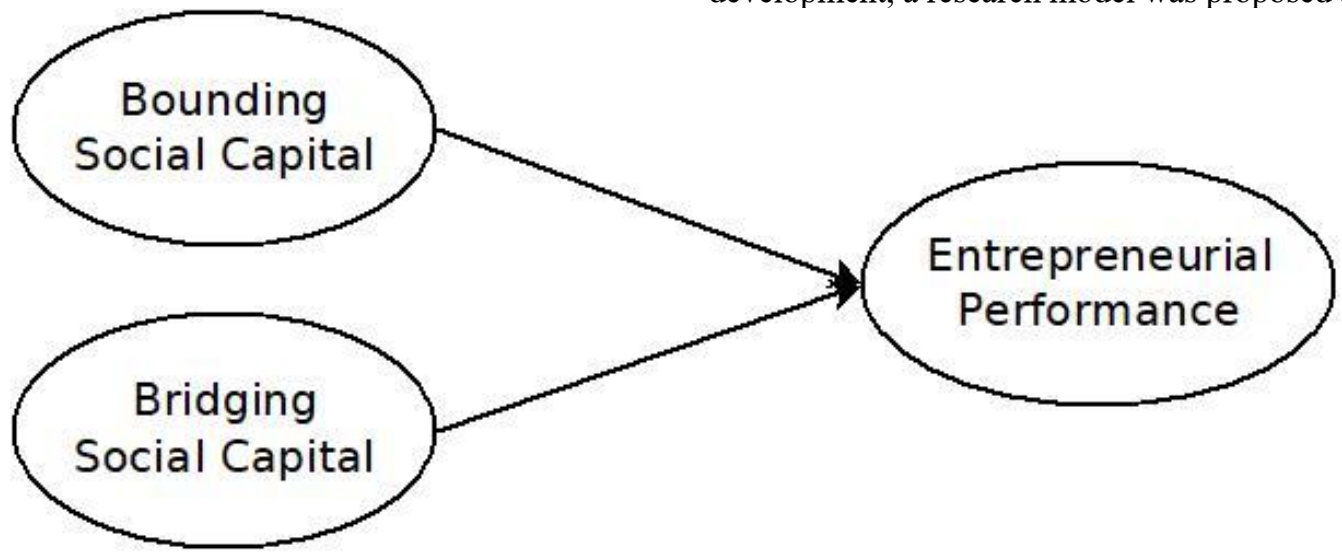

Figure 1. Research Model 


\section{Research Method}

Based on literature review, the measurement of bonding social capital and bridging social capital were modified from Subramaniam \& Youndt [6] and Han \& Hovav [7]. Scales to measure entrepreneurial performance were adapted from Cooper and Artz [8]. Questionnaires were scored on a seven-point Likert scale. After removing invalid questionnaires, 326 valid responses were analyzed by the SPSS and AMOS.

\section{Analysis Results}

In the sample, $50.6 \%$ was male and $49.4 \%$ was female. Furthermore, $44.8 \%$ aged under 30 while $43.3 \%$ was 30 40 years old. Only $32.5 \%$ hold college degree or above while $51.2 \%$ had high school graduated. Respondents were single account for $20.9 \%$, and $66.6 \%$ were married but had no child.

\subsection{Measurement model}

\subsubsection{Construct validity}

As shown in Table I, all standardized factor loadings of questions are from 0.712 to 0.838 . All composite reliability (CR) of the constructs ranging from 0.866 to 0.905 exceed 0.7 recommended by Nunnally and Bernstein (1994) indicating all constructs have internal consistency. Lastly, average variance extracted (AVE) of constructs ranging from 0.563 to 0.655 , exceeding 0.5 suggested by Hair et al. (2010), and Fornell and Larcker (1981). These results demonstrated all measurement items had convergent validity.

Table I. Results for the measurement model

\begin{tabular}{ccccc}
\hline & & & Reliability & Convergent Validity \\
\cline { 3 - 5 } Construct & Item & Std. factor loading & CR & AVE \\
\hline & & & 0.866 & 0.563 \\
Bridging & BRSC1 & 0.768 & & \\
Social Capital & BRSC2 & 0.780 & & \\
& BRSC3 & 0.725 & & \\
& BRSC4 & 0.712 & & \\
& BRSC5 & 0.765 & & \\
Bounding & BOSC1 & 0.788 & & \\
Social Capital & BOSC2 & 0.780 & & \\
& BOSC3 & 0.749 & & \\
& BOSC4 & 0.817 & & \\
& BOSC5 & 0.770 & & \\
& BOSC6 & 0.735 & & \\
Entrepreneurial & EP1 & 0.796 & & \\
Performance & EP2 & 0.838 & & \\
& EP3 & 0.780 & & \\
& EP4 & 0.809 & & \\
& EP5 & 0.822 & \\
\hline
\end{tabular}

\subsubsection{Discriminant validity}

This study examined discriminant validity of the measurement model with AVE. Fornell \& Larcker [9] considered that if the square root of AVE for each construct is greater than the correlation coefficient, the model has appropriate discriminant validity. Since the Table II shows the measurement model has an appropriate construct validity, it also indicated that the results were not largely affected by Common Method Bios.

Table II. Discriminant validity for the measurement model.

\begin{tabular}{ccccc}
\hline & AVE & $\begin{array}{c}\text { Bridging } \\
\text { Social } \\
\text { capital }\end{array}$ & $\begin{array}{c}\text { Bounding } \\
\text { Social } \\
\text { capital }\end{array}$ & $\begin{array}{c}\text { Entrepreneurial } \\
\text { Performance }\end{array}$ \\
\hline $\begin{array}{c}\text { Bridging } \\
\text { Social } \\
\text { capital }\end{array}$ & 0.563 & $\mathbf{0 . 7 5}$ & & \\
$\begin{array}{c}\text { Bounding } \\
\text { Social } \\
\text { capital }\end{array}$ & 0.598 & 0.768 & $\mathbf{0 . 7 7 3}$ & \\
$\begin{array}{c}\text { Entrepreneurial } \\
\text { Performance }\end{array}$ & 0.655 & 0.694 & 0.695 & $\mathbf{0 . 8 0 9}$ \\
\hline
\end{tabular}




\subsubsection{Structural model analysis}

The structural model was analyzed by maximum likelihood estimation. The analysis results included model fit, hypothesis tests and $\mathrm{R}^{2}$. In this study, 9 model fit indexes were adopted from Jackson et al. [10] to report the test results. Table III showed all model fit indexes met the suggested criteria. Therefore, the research model has a good fit.

Table III. Model fit

\begin{tabular}{ccc}
\hline Index & Criteria & Value \\
\hline$\chi^{2}$ & better smaller & 270.995 \\
DF & better larger & 101.000 \\
$\chi^{2} / \mathrm{DF}$ & $1<\chi^{2} / \mathrm{DF}<3$ & 2.683 \\
RMSEA & $<0.08$ & 0.072 \\
SRMR & $<0.08$ & 0.039 \\
TLI (NNFI) & $>0.9$ & 0.938 \\
CFI & $>0.9$ & 0.948 \\
GFI & $>0.9$ & 0.92 \\
AGFI & $>0.9$ & 0.905
\end{tabular}

In Table IV, the path coefficient of bridging social capital to entrepreneurial performance is $(b=0.389, p<$ 0.001 ), and bounding social capital to entrepreneurial performance is $(\mathrm{b}=0.354, p<0.001)$

The results support the research hypotheses $\mathrm{H} 1$ and H2. The explanatory power of both bridging social capital and bounding social capital can explain $54.6 \%$ of entrepreneurial performance.

Table IV. Regression coefficient

\begin{tabular}{cccccc}
\hline $\begin{array}{c}\text { Depend } \\
\text { variable }\end{array}$ & Independ variable & $\begin{array}{c}\text { Unstd. } \\
\text { S.E. }\end{array}$ & $\begin{array}{c}\text { Std. } \\
\text { S.E. }\end{array}$ & $\begin{array}{c}\text { Unstd. } \\
\text { S.E./Std. } \\
\text { S.E. }\end{array}$ & $\mathbf{R}^{\mathbf{2}}$ \\
\hline $\mathrm{EP}$ & $\mathrm{BRSC}$ & 0.389 & 0.087 & $4.495^{* * *}$ & 0.546 \\
& $\mathrm{BOSC}$ & 0.354 & 0.077 & $4.610^{* * *}$ & \\
\hline
\end{tabular}

$\mathrm{EP}=$ Entrepreneurial Performance; $\mathrm{BRSC}=$ Bridging Social Capital; $\mathrm{BOSC}=$ Bounding Social Capital; ${ }^{* * *}=p<0.001$

\section{CONCLUSIONS}

This study has found that both the bounding social capital and the bridging social capital have a significant positive impact on entrepreneurial performance. Agricultural entrepreneurs should win the support of relatives and friends, strengthen the relationship, maintain contacts, and obtain more bounding social capital. On the other hand, they should obtain heterogeneous resources, accumulate bridging social capital, and promote the smooth development of agricultural entrepreneurship activities.

This study enriches the research on the influencing factors of entrepreneurial performance of agricultural entrepreneurs, provides a new idea for the study of social capital of agricultural entrepreneurs, and verifies the important role of entrepreneurial ability of individual entrepreneurs on entrepreneurial performance.

Social capital is only one of the influencing factors of entrepreneurial performance. Future research can carry out a comprehensive analysis of the impact of other factors on entrepreneurial performance, or consider the intermediary factors of agricultural entrepreneurs' social capital on entrepreneurial performance, and reveal the specific path of its role.

\section{Acknowledgment}

The paper is supported by the Fujian Business University through grant no. 2019sysk08.

\section{REFERENCES}

1. Lin N. Social capital. A theory of social action and structure[J]. 2001.

2. Putnam R D. Bowling alone: The collapse and revival of American community[M]. Simon and schuster, 2000.

3. Wernerfelt B. A resource-based view of the firm[J]. Strategic management journal, 1984, 5(2): 171-180.

4. Davidsson, P., \& B. Honig, 2003, "The Role of Social and Human Capital among Nascent Entrepreneurs", Journal of Business Venturing, 18(3), pp. 301-331.

5. Ozgen E, Baron R A. Social sources of information in opportunity recognition: Effects of mentors, industry networks, and professional forums[J]. Journal of business venturing, 2007, 22(2): 174-192.

6. Subramaniam M, Youndt $M$ A. The influence of intel- lectual capital on the types of innovative 
capabilities [J]. Academy of Management Journal, 2005, 48 (3): 450-463.

7. Han J Y, Hovav A. To bridge or to bond? Diverse social connections in an IS project team[J]. International Jour- nal of Project Management, 2013, 31(3): 378-390.

8. Cooper A C, Artz K W. Determinants of satisfaction for entrepreneurs[J]. Journal of Business Venturing, 1995, 10(6): 439-457.
9. Fornell C, Larcker D F. Evaluating structural equation models with unobservable variables and measurement error[J]. Journal of marketing research, 1981, 18(1): 39-50.

10. Jackson, D. L., Gillaspy Jr, J. A., \& Purc-Stephenson, R. (2009). Reporting practices in confirmatory factor analysis: an overview and some recommendations. Psychological methods, 14(1), 6. 